\title{
Ironi Dalam Bahasa Kiasan Punjabi: Analisis Semantik Inkuisitif
}

\author{
Irony in Punjabi Language: An Inquisitive Semantic Analysis \\ BALVEEN KAUR* \& MARY FATIMAH SUBET \\ Fakulti Bahasa dan Komunikasi. Universiti Malaysia Sarawak, \\ 94300 Kota Samarahan, Sarawak, Malaysia. \\ * Corresponding author: veen_5096@yahoo.com
}

\begin{abstract}
ABSTRAK
Bahasa merupakan satu medium penyampaian pelbagai hasrat yang berkesan. Kajian ini mengkaji bahasa kiasan Punjabi yang digunakan oleh masyarakat Sikh di Malaysia. Objektif kajian adalah untuk mengenal pasti unsur haiwan dalam bahasa kiasan Punjabi. Kajian ini berbentuk kualitatif. Lima bahasa kiasan yang berunsurkan haiwan yang dikutip melalui kaedah temu bual dianalisis berdasarkan pendekatan semantik inkuisitif Nor Hashimah Jalaluddin (2014). Hasil kajian mendapati bahawa ada beberapa nasihat melalui bahasa kiasan yang memasukkan unsur haiwan dalam ujarannya. Didapati makna pada peringkat permukaan semantik, cuma memaparkan makna selapis sahaja. Dengan pendekatan semantik inkuisitif, dapatan kajian menunjukkan penyebutan unsur haiwan dalam ujaran bahasa kiasan masyarakat Punjabi berbaur ironi dan mempunyai falsafah kehidupan masyarakat ini. Setiap bahasa kiasan yang dianalisis memaparkan makna berlapis yang perlu dikupas dengan mengaitkan makna selapis berkenaan dengan kehidupan masyarakat Punjabi secara keseluruhan yang merangkumi aspek norma dan pemikiran mereka serta tindak tanduk kehidupan yang mereka harungi seharian. Kajian juga mendapati bahawa ujaran kiasan ini dicipta berdasarkan pengamatan terhadap persekitaran dan alam pemikiran mereka yang berbentuk abstrak dan memerlukan pengamatan teliti. Akhirnya, didapati bahawa pendekatan semantik inkuisitif yang menggabungjalinkan data, teori, kognitif, falsafah dan akal budi sesebuah masyarakat dapat memaparkan makna sebenar yang hendak disampaikan menerusi bahasa kiasan ini. Dengan kaedah semantik skrip, makna selapis mudah diketahui. Kemudian dengan semantik resonans, pemetaan makna selapis ini dikaitkan dengan kognitif penutur dan akhirnya dengan analisis semantik inkuisitif, makna yang lebih deskriptif dapat dijelmakan. Kaitan makna dapat dikonstruk satu per satu dengan tiga peringkat analisis dalam semantik inkuisitif. Makna yang diperoleh lebih tinggi kesahannya.
\end{abstract}

Kata kunci: bahasa kiasan, masyarakat Punjabi, falsafah dan akal budi, semantik, semantik inkuisitif.

\begin{abstract}
Language is a medium of delivering variety of effective desires. This study examines the Punjabi language used by the Sikhs in Malaysia. The objective of the study is to identify animal elements in the Punjabi figurative language. This study is qualitative. The five animal figurative languages cited by the interview method were analyzed based on the inquisitive semantic approach Nor Hashimah Jalaluddin (2014). The findings suggest that there are some advice through figurative language that incorporates animal elements in his speech. The meanings of the semantic surface mean that it only shows the meaning of a layer. With the inquisitive semantic approach, the findings of the study show the mention of animal elements in the speech of the folklore language of the societal society mixed with irony and have the philosophy of the life of this society. Each figurative language analyzed illustrates the layered meaning that needs to be peered by linking the meanings of the society to the whole of society as well as aspects of their norms and thoughts as well as the actions of their daily life. Studies have also found that these metaphysical utterances are based on observations of their abstract-shaped environment and nature and require careful observation. Finally, it is found that the inquisitive semantic approach that combines the data, theories, the cognition and the philosophy and the minds of a society can reveal the true meaning to be conveyed through this metaphorical language. With the semantics of the script, the meaning of the simplest is known. Then with the semantics of resonance, the mapping of the meaning of this layer is associated with the cognitive of the speaker and ultimately with the inquisitive semantic analysis, a more descriptive meaning can be manifested. The connotation of the meaning can be constructed one by one with three levels of analysis in semantic incuity. The meanings obtained are higher in legality.
\end{abstract}

Keywords: Figurative languages, Punjabi community, philosophy, mind, semantic, inquisitive semantic.

Copyright: This is an open access article distributed under the terms of the CC-BY-NC-SA (Creative Commons AttributionNonCommercialShareAlike 4.0 International License) which permits unrestricted use, distribution, and reproduction in any medium, for non-commercial purposes, provided the original work of the author(s) is properly cited. 


\section{PENGENALAN}

Hubungan bahasa dan pemikiran telah banyak dikaji oleh pengkaji-pengkaji bahasa yang meliputi hal-hal yang berkaitan bidang linguistik, khususnya semantik. Dalam bidang semantik, antara isu yang dibangkitkan berkaitan aspek ini ialah makna implisit yang terdapat dalam bahasa bermetafora. Pelbagai pendekatan semantik dan pragmatik yang mengkaji makna secara lebih tepat digunakan. Misalnya kajian yang dilakukan oleh Rogayah (2012), Rozaimah Rashidin \& Nor Hashimah Jalaluddin (2015), Suziana Mat Saad, Nor Hashimah Jalaluddin, \& Imran-Ho Abdullah (2017), dan Mary Fatimah Subet (2018). Dalam masyarakat Punjabi, bahasa bermetafora ini dapat diamati dalam bentuk bahasa kiasan atau nama lain dalam bahasa Punjabi ialah muhavare. Namun, fokus pengkaji dalam kajian ini ialah cabang ilmu semantik yang mengkaji maksud di sebalik sesuatu ayat dalam satu bahasa yang tertentu. Menurut Anis Kurniawan (2015), "semantik adalah cabang linguistik yang mempelajari makna yang terkandung dalam bahasa, kode, atau jenis lain dari representasi. Dengan kata lain, semantik ialah kajian tentang makna sesuatu perkataan atau ayat. "Semantik merupakan kajian makna yang boleh didampingi oleh mana-mana bidang dalam memperjelaskan lagi tabii bahasa yang dikaji” (Nor Hashimah Jalaluddin, 2009). Kajian bahasa kiasan seperti peribahasa dan simpulan bahasa sering menjadi tumpuan utama dalam kajian semantik.

Dalam kajian ini pengkaji akan memfokuskan kiasan yang bersifat ironi. Menurut Fauzi Rahman (2011), ironi ialah satu pengucapan yang dituturkan dengan mempunyai makna kebalikannya. Ironi yang membawa maksud sindiran akan dikaji dalam kiasan Bahasa Punjabi yang digunakan oleh orang Punjabi dengan menggunakan unsur haiwan. Ironi ini akan dikaji dengan memperlihatkan teori semantik inkuisitif yang diasaskan oleh Nor Hashimah Jalaluddin (2014) dalam mengupas akal budi yang terdapat dalam pemikiran orang Punjabi ketika menuturkan bahasa kiasan tersebut. Kajian ini adalah untuk mengkaji unsur haiwan dalam bahasa kiasan Punjabi yang bersifat ironi melalui kaca mata semantik inkuisitif dalam memperlihatkan akal budi orang Punjabi. Objektif utama kajian ini adalah untuk mengkaji bahasa kiasan Punjabi yang bersifat ironi iaitu sindiran, berunsurkan haiwan dalam menghubungkaitkan semantik inkuisitif dengan menunjukkan akal budi orang Punjabi. Objektif khusus dalam kajian pengkaji adalah untuk mengenal pasti dan menyenaraikan bahasa kiasan dalam bahasa Punjabi yang mengandungi unsur haiwan, menganalisis bahasa kiasan Punjabi yang mempunyai unsur haiwan dengan pendekatan semantik melalui tahap semantik skrip, semantik resonans dan semantik inkuisitif, dan menghubungkaitkan makna bahasa kiasan Punjabi yang mengandungi unsur haiwan dengan akal budi dan falsafah masyarakat Punjabi. Ada beberapa kajian yang terkini yang mengkaji kewujudan haiwan dalam kajian mereka misalnya kajian Suriati Zakaria dan Nor Hashimah Jalaluddin (2016) yang menyentuh spesies haiwan kera dalam cerita klasik Melayu, iaitu siamang putih. Namun, kajian ini tidak melihat kera itu secara tuntas kerana tumpuan kajian ini ialah melihat konsep ruang dalam Hikayat Anggun Che Tunggal.

\section{DATA DAN METODOLOGI}

Kajian ini ialah kajian kualitatif, iaitu data dikumpul melalui hasil temu bual dengan informan berbangsa Punjabi. Tiga orang informan ditemu bual untuk mendapatkan data kiasan dalam Bahasa Punjabi yang berunsurkan haiwan. Kesemua informan tersebut merupakan orang Sikh yang berasal dari Malaysia. Masing-masing informan mempunyai taraf pendidikan yang berbeza. Namun, bagi mencungkil lagi makna kiasan dengan lebih mendalam, pengkaji hanya menggunakan tiga orang informan. Salah seorang informan mempunyai taraf pendidikan menengah atas iaitu tingkatan 5, serta mempunyai pengetahuan yang mendalam tentang bahasa Punjabi kerana individu tersebut yang berumur lingkungan 70-80 tahun. Seorang lagi informan merupakan paderi di Gurdwara dan mempunyai banyak pengetahuan tentang agama Sikh serta bahasa kiasan Punjabi. Seorang lagi informan merupakan individu yang berasal dari India serta mempunyai pemahaman yang lebih mengenai bahasa kiasan Punjabi. Perbezaan taraf pendidikan serta kefahaman informan dalam kiasan Punjabi dapat membantu pengkaji membezakan nilai kefahaman sekali gus mendapat data yang sahih dalam penggunaan unsur haiwan bagi kiasan Punjabi.Hal ini kerana menurut Mohd Majid Konting (2005), pemboleh ubah-pemboleh ubah (dalam konteks kajian ini melibatkan latar belakang informan yang pelbagai) seperti jantina, taraf pendidikan, pendapatan, tempat tinggal dan sebagainya telah sedia wujud dan penyelidik tidak boleh mengawal dan memanipulasi pemboleh ubahpemboleh ubah ini semata-mata untuk memenuhi kehendak kajian. Nilai pemboleh ubah-pemboleh ubah ini adalah berbeza antara satu sama lain, dan juga berbeza antara individu.

Oleh itu, kajian ini berpendapat perbezaan taraf pendidikan serta kefahaman informan akan membolehkan penyelidik mendapat pelbagai maklumat yang berbeza untuk kedapatan kajian data yang lebih sahih. Data sahih yang dimaksudkan ini ialah data asli bahasa kiasan yang dikutip daripada temu bual dengan informan tadi dan data ini seterusnya dapat diuji kesahannya dengan pendekatan semantik inkuisitif yang diaplikasikan dalam kajian ini. Hal ini kerana menurut Othman Mohamed (2001), penyelidik akan menggunakan analisis data dalam penyelidikannya bagi membuat sesuatu kesimpulan dan perakuan sebagai hasil penyelidikan. Oleh itu, kajian ini perlu kepada data yang sahih yang dikutip secara langsung daripada informan yang mewakili masyrakat yang mendokong bahasa kiasan Punjabi ini. Data yang dikutip ialah data mentah yang asli kerana daripada penelitian 
terhadap kajian-kajian lepas, didapati bahawa tiada dokumentasi dilakukan terhadap bahasa kiasan Punjabi. Pendekatan semantik inkuisitif Nor Hashimah Jalaluddin (2014) diaplikasi dalam kajian ini, iaitu mengupas maksud sesuatu kiasan melalui tiga tahap. Tiga tahap yang dimaksudkan ialah semantik skrip, semantik resonans dan semantik inkuisitif. Tahap semantik skrip cuma mengemukakan maksud bagi setiap perkataan dalam kiasan secara harfiah. Tahap semantik resonans pula mengetengahkan analisis data dengan teori yang dikaitkan dengan tahap kognitif di sebalik penciptaan atau penggunaan kiasan tersebut, sementara pada tahap semantik inkuisitif, analisis makna menjangkau lebih jauh lagi dengan mengaitkan makna yang diperoleh pada dua tahap terawal tadi dengan mengaitkannya pula dengan falsafah dan akal budi masyarakat Punjabi. Maka tiga tahap analisis ini akan dapat memperlihatkan maksud di sebalik setiap haiwan yang digunakan dalam kiasan tersebut. Dalam kajian ini sebanyak 25 kiasan telah dikumpul. Menurut Syed Arabi Aidid (1992), dalam Muhammad Fauzi Jumingan (2003), pemilihan sampel yang terlalu banyak tidak semestinya melambangkan ketepatan dapatan yang diingini. Dalam kajian ini pengkaji memfokus kepada kiasan yang berunsur ironi sahaja dan kesemua 25 data tersebut menepati kehendak pengkaji. Namun untuk keperluan kertas kerja ini, lima data sahaja akan dibincangkan berdasarkan tiga tahap analisis semantik inkuisitif iaitu semantik skrip, semantik resonans dan semantik inkuisitif.

\section{ANALISIS DAN PERBINCANGAN}

Tahap pertama analisis data di atas dilakukan pada peringkat semantik skrip. Dari segi makna skripnya, dalam kiasan Meri billi menu meow sepertia pada Jadual 1membawa maksud bahawa individu X telah banyak memberi ilmu atau membantu individu Y, kemudian individu Y pula yang menggunakan segala ilmu itu terhadap individu $\mathrm{X}$. Ilmu dalam kiasan ini bersifat luas. Ilmu ini bukan sekadar pengetahuan tetapi juga termasuk nasihat atau pengalaman yang dilalui oleh seseorang individu.

Jadual 1. Semantik krip kiasan Meri billi menu meow

\begin{tabular}{lllll}
\hline Kiasan Punjabi & meri & billi & menu & meow \\
\hline $\begin{array}{l}\text { Terjemahan } \\
\text { langsung }\end{array}$ & $\begin{array}{l}\text { Kepunyaan } \\
\text { saya }\end{array}$ & kucing & saya & mengeow \\
\hline
\end{tabular}

Terjemahan gramatis : Kucing saya mengeow saya.

Makna $\quad$ : individu X mengajar balik apa yang diajar oleh individu Y sebelumnya.

Setelah makna skrip diperoleh, tahap analisis seterusnya ialah analisis peringkat resonans. Tahap ini memperlihatkan peranan kognitif mengambil fokus interpretasi. Mengapa haiwan kucing (billi) yang digunakan? Secara biologinya, seekor kucing mempunyai penglihatan serta pendengaran yang sangat tajam jika ingin dibandingkan dengan haiwan lain terutamanya anjing (Effendi Cacang \& Budiana, 2004). Dengan penglihatan yang tajam seeokor kucing boleh melihat sesuatu tindakan mahupun sesuatu perlakuan dan dapat menangkap maksudnya dengan cekap. Selain itu, bersama-sama penglihatan, pendengaran seekor kucing yang tajam juga membantu kucing untuk memahami sesuatu yang diajar. Dengan kombinasi pendengaran dan penglihatan yang mantap, seekor kucing boleh mengadaptasi atau menghadam sesuatu maksud atau ilmu yang ingin disampaikan oleh sesiapa. Sifat kucing yang sangat menyenangkan juga mudah untuk mengajar mereka serta sifat mereka yang sangat tenang memudahkan seseorang untuk mendekati kucing. Namun, di sebalik sifat-sifat positif seekor kucing terselit juga sifatnya yang negatif, iaitu seekor kucing mempunyai sifat yang agak memilih. Jika seekor kucing mudah bergaul dengan mesra, ia boleh menjadi sahabat manusia tetapi jika berlaku disebaliknya, ia akan menimbulkan masalah (Effendi Cacang \& N.S. Budiana, 2004). Sifat-sifat yang dinyatakan ini dapat dikaitkan dengan kiasan tersebut; dengan penglihatan dan pendengaran yang tajam, seekor kucing boleh belajar dengan pantas tetapi jika kucing itu mengalami kesukaran untuk bergaul, kucing itu juga boleh bertindak negatif dengan menggunakan semula ilmu yang dipelajari terhadap mangsa.

Setelah tahap makna skrip dan resonans dirungkai, falsafah serta akal budi masyarakat yang mencipta kiasan ini pula diselongkar. Hal ini demikian, mesti ada alasan kukuh di sebalik penciptaan bahasa kiasan ini yang memaparkan penggunaan unsur haiwan. Analisis peringkat semantik inkuisitif pula mengambil tempatnya. Melihat kepada akal budi dan falsafah dalam masyarakat Punjabi, menurut informan (Satwan Kaur, komunikasi lisan, November 3, 2017), kisah seekor kucing merupakan satu cerita rakyat dalam masyrakat Sikh. Kucing merupakan seekor binatang yang bijak kerana kucing mengajar singa segala ilmu yang harus ada pada seekor kucing. Jadi, kucing mengajar singa cara memburu, mengejar mahupun cara menyerang. Selepas mendapat segala ilmu tersebut, singa mula menunjuk belangnya dan cuba menyerang kucing itu. Namun, kucing bertindak bijak dengan memanjat pokok. Singa terpinga-pinga dan bertanya kepada si kucing mengapa tidak mengajarnya memanjat pokok. Jawab si kucing, kerana jika diajarnya segala ilmu, singa pula akan menelannya. Oleh itu, kucing hanya mengajar beberapa perkara kerana tidak mahu apa yang diajarnya memakan dirinya semula suatu hari nanti. 
Jadi, kiasan meri billi menu meow digunakan oleh masyarakat Punjabi dalam menyindir sesiapa sahaja yang cuba melawan pengajarnya dengan niat yang kurang baik.

Data seterusnya memperlihatkan kiasan yang menghasilkan makna harfiah tentang seekor anjing (kutta) akan sentiasa mengekalkan sifatnya sama ada yang positif atau negatif kerana anjing sering kali diberi gelaran seekor haiwan yang setia. Kesetiaan dapat dilihat apabila anjing patuh dengan arahan tuannya dan menjaga keselamatan tuannya. Anjing juga mudah mengenali insan yang baik dan jahat melalui derianya, namun terdapat juga anjing liar yang boleh mengancam nyawa (Horowitz, 2009).

Bagi analisis peringkat resonans seperti di dalam kiasan ini, pemikiran yang dapat dilihat ialah dengan sifat manusia yang kejam atau jahat dikaitkan dengan ekor anjing (kuttey dhi pooch) kerana ekor anjing tidak pernah lurus dan sentiasa bengkok atau serong. Begitu juga dengan sifat manusia yang melakukan perbuatan yang serong. Jika seseorang sudah terlibat dengan satu perbuatan jahat, perlakuan itu akan menjadi tabiat sehingga menyebabkan kesukaran untuk seseorang itu berubah. Situasi ini dapat dikaitkan dengan kiasan seperti dalam Jadual 2, iaitu seorang insan yang mempunyai sifat yang buruk atau tabiat yang sukar untuk diubah, sering dikaitkan dengan ekor anjing yang juga tidak pernah menjadi lurus.

Peringkat inkuisitif pula memunculkan persoalan ini. Mengapa anjing pula yang dikaitkan? Bukan semua anjing baik dan sentiasa menjaga tuannya, malah terdapat juga anjing yang mempunyai sifat yang ganas dan boleh menyerang manusia. Oleh itu, sifat anjing yang buas serta manusia yang mempunyai tabiat buruk yang tidak boleh berubah dapat dikaitkan dengan kiasan tersebut. Menurut informan (Gurbir Singh, komunikasi lisan, October 26, 2017), perkaitan tersebut dapat dihubungkan dalam sebuah cerita rakyat iaitu dengan ekor seekor anjing. Pada suatu ketika dahulu, seorang lelaki Sikh telah mengikat seruling di ekor anjing, dengan mengharap ekornya akan menjadi lurus. Dibiarkan seruling itu diikat agak lama pada ekor anjing, namun lepas tempoh yang lama, ekor anjing itu tetap serong dan tidak lurus. Walaupun dicuba perkara yang sama berulang kali, ekornya tetap tidak

Jadual 2. Analisis peringkat resonans makna harfiah tentang seekor anjing

\begin{tabular}{llllllll}
\hline Kiasan Punjabi & kuttey & dhi & pooch & kadhe & sidhi & nayi & hondhi \\
\hline $\begin{array}{l}\text { Terjemahan } \\
\text { langsung }\end{array}$ & anjing & punya & ekor & tidak & lurus & akan & pernah \\
\hline
\end{tabular}

Terjemahan gramatis : ekor anjing tidak pernah akan lurus

Makna $\quad$ : Seseorang yang jahat akan kekal jahat dan tidak akan insaf.

lurus , justeru masyarakat Sikh menganggap bahawa ekornya memang degil serta falsafah orang zaman dahulu yang unik iaitu dikaitkannya dengan sifat manusia yang negatif. Oleh itu, kiasan seperti kuttey dhi pooch kadhe sidhi nayi hondhi menyamai individu yang tidak mengubah sikapnya yang negatif.

Pada Jadual 3, makna skrip bagi kiasan Gha da ghou cheriya chitte tere mu tey pyangey ialah jika seseorang itu mengacau najis lembu, kita juga yang akan menjadi kotor. Ingin ditegaskan disini ialah, jika seseorang berbuat jahat kepada kita, jangan kita membalasnya dengan perbuatan yang jahat juga kerana diri kita sendiri akan menerima padah. Makna ini sangat jelas.

Jadual 3. Makna skrip bagi kiasan Gha da ghou cheriya chitte tere mu tey pyangey

\begin{tabular}{llllllllll}
$\begin{array}{l}\text { Kiasan } \\
\text { Punjabi }\end{array}$ & Gha & $d a$ & ghou & cheriya & chitte & tere & mu & tey & pyengey \\
\hline $\begin{array}{l}\text { Terjemahan } \\
\text { langsung }\end{array}$ & lembu & punya & najis & kacau & tempias & kamu & muka & pada & kena \\
\hline
\end{tabular}

\begin{tabular}{ll}
\hline Terjemahan gramatis & : mengacau najis lembu akan terpericik ke muka sendiri \\
Makna & : Kalau seseorang membalas balik kejahatan pada orang yang memang \\
& sudah bermasalah, kita juga yang akan menimpa padah
\end{tabular}

Namun, jika difikirkan secara kognitifnya, padah yang diterima dapat dikaitkan dengan kiasan tersebut ialah najis lembu kerana najis itu sendiri merupakan sesuatu yang kotor dan busuk serta kiasan ini dikaitkan dengan insan yang buat perkara jahat. Apabila seseorang terkena tempias najis itu, individu tersebut akan diselubungi kekotoran. Jadi, pemikiran masyarakat Sikh yang ingin disampaikan dalam kiasan ini ialah najis lembu itu umpama manusia yang bertindak jahat, namun jangan kita menyentuh najis tersebut iaitu membalas dengan perbuatan yang sama, 
kerana kita juga yang akan mendapat tempiasnya. Kiasan ini menjadi semakin menarik apabila falsafah dan akal budi masyarakat Sikh dikaitkan dengan penciptaannya. Peringkat ini menerbitkan persoalan seperti mengapa najis lembu yang digunakan oleh masyarakat Punjabi? Kenapa tidak najis ayam atau najis kambing?

Hal ini demikian kerana masyarakat Punjabi di India, banyak membela lembu bagi sumber pendapatan mereka. Lembu digunakan untuk aktiviti pertanian dan juga susu lembu amat penting dalam kehidupan masyarakat Sikh (Sarjit Singh, 1999). Hampir setiap upacara keagamaan yang dibuat menggunakan susu lembu iaitu pemberian Karha Prasaad (manisan yang dibuat daripada susu lembu). Menurut informan (Satwan Kaur, komunikasi lisan, November 3, 2017), masyarakat Punjabi dahulu menggunakan najis lembu (thappi) sebagai bahan api kerana tiada arang digunakan. Proses thappi itu bermula dengan mengumpul najis lembu itu secara bulat seperti batu, kemudian dikeringkan bawah matahari terik agar menjadi keras. Pengumpulan najis itu dibuat dengan tangan iaitu mengambil najis itu dan membuatnya dalam bentuk bulat yang besar. Semasa membuat itu, najis boleh terpercik di muka atau badan jika tidak dilakukan dengan berhati-hati. Begitu juga dengan kiasan itu, iaitu jika kita membalas perbuatan yang jahat terhadap orang yang sudah bermasalah, kita sendiri akan ditimpa padah. Oleh itu, masyarakat Punjabi menggunakan kiasan gha dha ghou cheriya chitte tere mu tey pyangey kerana penggunaan najis lembu memberi cahaya di rumah sebagai bahan api, tetapi jika cara penggunaan najis itu tidak betul dan menyebabkan kekotoran, maka tiada cahaya yang dapat dihasilkan. Menjurus kepada sikap manusia, jika dibalas perbuatan jahat kepada insan yang sudah bermasalah, kita juga yang akan ditimpa malang.

Avdha ghora na pajayi ja membawa makna skrip nya sebagai seseorang yang menuturkan sesuatu tanpa fakta mahupun hanya menipu dan mereka cerita. Istilah kuda (ghora) dan laju (pajayi) seperti pada Jadual 4 digunakan kerana seekor kuda berlari dengan laju dan begitu juga, apabila seseorang mengungkapkan sesuatu pertuturan ia diungkapkan dengan begitu pantas tetapi tidak menepati perkara yang sebenar.

Jadual 4. Makna skrip bagi kiasan Avdha ghora na pajayi ja

\begin{tabular}{llllll}
\hline Kiasan Punjabi & Avdha & ghora & na & pajayi & ja \\
\hline $\begin{array}{l}\text { Terjemahan } \\
\text { langsung }\end{array}$ & kamu & kuda & jangan & laju & terus \\
\hline $\begin{array}{l}\text { Terjemahan gramatis } \\
\text { Makna }\end{array}$ & $\begin{array}{l}\text { : Jangan menunggang kuda kamu dengan laju } \\
\text { : Seseorang yang bercakap tanpa fakta yang sahih (melibatkan unsur } \\
\text { dongeng) }\end{array}$ & & \\
& & &
\end{tabular}

Tidak dapat disangkal secara fizikalnya, seekor kuda ialah binatang yang kuat dan pantas. Pada zaman dahulu, tenaga kuda sangat diperlukan oleh perajurit sewaktu berperang kerana zaman dahulu kuda merupakan satusatunya pengangkutan yang laju dan boleh sampai ke lokasi berperang dengan pantas. Ketiadaan tulang selangka yang menyebabkan kuda berlari dengan pantas dan lebih lebar (Bowling \& Ruvinsky, 2000). Kuda sehingga sekarang digunakan dalam perlumbaan, iaitu kuda berlari tanpa henti dan tanpa halangan. Kelajuan kuda terserlah di litar balapan tersebut. Begitu juga jika dikaitkan dengan lidah manusia yang mudah mengeluarkan kata-kata tanpa berfikir. Apa sahaja yang diungkapkan tidak boleh ditelan semula kerana percakapan manusia laju seperti larian seekor kuda. Hal ini dapat diselongkar dengan analisis peringkat resonans yang mengaitkan kognitif di sebalik ciptaan kiasan ini.

Falsafah serta akal budi masyarakat Punjabi ditelusuri seterusnya untuk mengesan makna sebenar di sebalik ciptaan kiasan ini yang memaparkan penggunaan unsur kuda ini. Menurut (Amarjit Kaur, komunikasi lisan, Oktober 16, 2017), masyarakat Punjabi mempunyai hubungan yang rapat dengan kuda. Hubungan ini terserlah dalam peperangan semasa pada zaman Guru Gobind Singh. Pakatan Mughal menentang beliau dan ingin menguasai tanah yang dimiliki oleh Guru Gobind Singh. Dalam penghijrahan penduduk kampung serta dalam peperangan hanya kuda yang digunakan sebagai pengangkutan. Kuda hanya mengikut rentak individu yang menanganinya. Dapat dilihat bahawa kuda hanya mengikut rentak yang dibawa oleh manusia tanpa mengetahui jalan yang dilalui itu membahayakan atau tidak, dan penyataan ini menjurus kepada ungkapan fakta yang tidak kukuh apabila seseorang mengungkapkan sesuatu yang tidak sahih. Guru Gobind Singh juga merupakan satusatunya guru yang mempunyai kuda baka 'Blue Roan'. Pada zaman dahulu, kuda Guru Gobind Singh digelar sebagai 'Neela Ghora' kuda biru atau 'Neelay ghoray they swaar' yang bermaksud penunggang si kuda biru. Guru Gobind Singh telah belajar seni tunggangan kuda dan dengan segala ilmu yang dipelajari beliau mengarah warga Sikh untuk menyediakan senjata dan kuda demi masa hadapan sebagai langkah keselamatan. Ungkapan langkah keselamatan itu membuktikan bahawa seekor kuda boleh digunakan pada saat-saat genting kerana kuda merupakan salah satu binatang yang boleh berlari laju. Jadi, akal budi masyarakat Sikh tentang kiasan avdha ghora na pajayi ja dapat dilihat sejak zaman Guru Gobind Singh lagi, kerana ungkapan manusia serta kelajuan seekor kuda tidak dapat dipisahkan. 
Desi kutta kureshani boli sperti pada Jadual 5 membawa maksud seseorang yang berlagak pandai, tetapi sebenarnya kurang pengetahuan tentang sesuatu perkara tersebut. Desi kutta iaitu anjing kampung digunakan dalam kiasan ini yang merujuk kepada anjing jalanan. Desi sendiri merujuk kepada orang Punjabi di kawasan kampung.

Mengapa anjing jalanan yang diperlihatkan sebagai seorang yang berlagak pandai? Hal ini demikian kerana seekor anjing mempunyai ciri yang sangat agresif dan berani berhadapan dengan apa-apa sahaja situasi. Walaupun anjing itu tidak mempunyai idea tentang apa yang sedang berlaku di sekelilingnya, ia tetap akan berada di situasi tersebut dan seolah-olah ia faham apa yang sedang berlaku (Horowitz, 2009).

Jadual 5. Makna skrip bagi kiasan Desi kutta kureshani boli

\begin{tabular}{|c|c|c|c|c|}
\hline Kiasan punjabi & desi & kutta & qureshy & boli \\
\hline Terjemahan langsung & kampung & anjing & Quresh & percakapan \\
\hline
\end{tabular}

Dalam memperlihatkan akal budi orang Punjabi, menurut informan (Amarjit Kaur, komunikasi lisan, Oktober 16, 2017), kiasan ini sangat berkait rapat dengan sejarah The history of Bhagat Singh. Sejarah ini mengisahkan tentang cara Bhagat Singh cuba mempertahankan hak di negara India daripada jajahan British. Pada masa dahulu, Pakistan dan India masih belum dipisahkan dan Bhagat Singh berasal daripada Lyallpur, Punjab India yang kini adalah di Pakistan selepas perpisahan sempadan. Namun, ada sesetengah rakyat di India bekerjasama dengan pihak British dan menimbulkan ketidakpuashatian sesetengah masyarakat, sehingga berlaku kejadian yang menjadi sejarah hitam masyarakat di India iaitu serangan di Jallianwala Bagh. General Dyer melancarkan serangan dengan menembak semua orang Sikh yang tidak bersalah dan isu tersebut menjadi panas sehingga Bhagat Singh mengambil keputusan untuk menghalau British. Golongan atasan yang bekerjasama dengan pihak British menganggap dirinya sama peringkat dengan British, sedangkan mereka tidak tahu apa yang sedang dimanipulasikan oleh pihak British. Golongan atasan iaitu penduduk masyarakat India, bersubahat dengan British demi kepentingan sendiri dianggap sebagai desi kutta dan qureshy boli dikaitkan dengan ungkapan kerjasama mereka dengan pakatan British, sedangkan orang desi (Punjabi) harus menuturkan bahasa Punjabi (Punjabi boli). Masyarakat India harus berkerjasama menghalau pihak British, namun demi kepentingan sendiri, mereka bersubahat dengan pihak British. Oleh itu, muncul kiasan seperti desi kutta kureshani boli bagi individu yang hanya berlagak pandai, sebaliknya kurang pengetahuan tentang kebenaran perkara.

\section{KESIMPULAN}

Kajian ini yang menggunakan pendekatan semantik inkuisitif melalui tahap semantik skrip, semantik resonans dan semantik inkuisitif dapat memperlihatkan falsafah dan akal budi masyarakat Punjabi. Hasil dapatan juga menunjukkan bahawa penggunaan unsur haiwan yang digunakan dalam kiasan menjurus kepada sifat negatif seseorang. Tuntasnya, kajian kiasan Punjabi yang mempunyai unsur haiwan menjadi satu sumber bukti berkaitan dengan pemikiran dan akal budi masyarakat Punjabi yang beranggapan haiwan dapat menyamai sifat manusia secara negatif. Melalui kiasan ini menunjukkan bahawa masyarakat Punjabi mempunyai pemikirannya yang tersendiri berkaitan dengan setiap jenis haiwan. Setiap haiwan menggambarkan makna implisit di sebalik setiap kiasan tersebut. Pengkaji mengaplikasikan teori semantik inkuisitif yang dapat memperlihatkan falsafah masyarakat Punjabi. Kajian ini bukan sahaja menyerlahkan segala kepercayaan, sejarah di sebalik adat atau budaya Punjabi, malah memperlihatkan cara hidup masyarakat Punjabi pada zaman dahulu melalui analisis kiasan tersebut. Kajian ini juga bukan sekadar menunjukkan akal budi masyarakat Punjabi, malah memberi ilham agar mengamalkan budaya yang diwarisi sejak dahulu supaya tidak hilang ditelan zaman. Kajian ini diharapkan memberi satu sumbangan terhadap bahasa kiasan Punjabi untuk didokumentasikan agar diketahui oleh masyarakat lain, di samping mengenali akal budi serta falsafah masyarakat Punjabi di sebalik kiasan berunsur haiwan yang bersifat ironi.

\section{RUJUKAN}

A.T. Bowling \& A. Ruvinsky. (2000). The genetics of the horse. New York, NY: CABI Publishing.

Anis Kurniawan. (2015). Pengertian semantik dan contohnya lengkap. Dimuat turun daripada http://www.gurupendidikan.com/pengertian-semantik-dan-contohnya-lengkap

Effendi, Cacang., \& N. S. Budiana. (2014). Kucing: Complete Guide Book For Your Cat. Jakarta, Indonesia: Agriflo.

Horowitz.A. (2009). Inside of a dog. London, UK. Simon and Schuster UK Ltd.

Mary Fatimah Subet. (2018). Analisis teori relevans dalam metafora. Jurnal Bahasa, 18(1). 159-188. 
Mohd Majid Konting. (2005). Kaedah Penyelidikan Pendidikan. Kuala Lumpur, Malaysia: Dewan Bahasa dan Pustaka.

Muhammad Fauzi Jumingan. (2003). Penterjemahan bahasa figuratif Arab Melayu: Satu analisis teori relevans. Tesis PhD. Bangi: Universiti Kebangsaan Malaysia.

Nor Hashimah Jalaluddin. (2009). Perkembangan Semantik Malaysia: Sorotan Ilmiah. Bangi, Malaysia: Penerbit Universiti Kebangsaan Malaysia.

Nor Hashimah Jalaluddin. (2014). Semantik dan akal budi Melayu. Bangi, Malaysia: Universiti Kebangsaan Malaysia.

Othman Mohamed. (2001). Penulisan tesis dalam bidang Sains Sosial Terapan. Serdang, Malaysia: Penerbit Universiti Putra Malaysia.

Rogayah Osman. (2012). Kesisteman Metafora Simpulan Bahasa: Analisis Semantik Kognitif. Tesis PhD. Bangi: Universiti Kebangsaan Malaysia.

Rozaimah Rashidin \& Nor Hashimah Jalaluddin. (2015). Metafora konsepsi emosi marah dalam data korpus teks tradisional melayu. Kertas kerja Seminar Linguistik Kebangsaan (SLIK 2015), Kuala Lumpur, Dewan Bahasa dan Pustaka. 20-21 Januari.

Sarjit Singh. (1999). Diaspora dan masalah identiti Sikh di Malaysia. Akademika 56 (Julai). 183 - 192.

Suriati Zakaria, \& Nor Hashimah Jalaluddin. (2016). Konsep ruang dalam anggun cik tunggal: Analisis semantik inkuisitif. GEMA Online ${ }^{\circledR}$ Journal of Language Studies, 16 (3). 187-204.

Suziana Mat Saad, Nor Hashimah Jalaluddin, \& Imran-Ho Abdullah. (2017). Kehidupan adalah perjalanan: analisis metafora konseptual dalam salina dan la vie devant soi. Jurnal Akademika. 87(1). 189-205.

Syed Arabi Idid. (1992). Kaedah Penyelidikan Komunikasi Dan Sains Sosial. Kuala Lumpur, Malaysia: Dewan Bahasa dan Pustaka. 